Cobblestone-like brain dysgenesis and altered glycosylation in congenital cutis laxa, Debré type

L. Van Maldergem, M. Yuksel-Apak, H. Kayserili, E. Seemanova, S. Giurgea, L. Basel-Vanagaite, E. Leao-Teles, J. Vigneron, M. Foulon, M. Greally, J. Jaeken, S. Mundlos and W. B. Dobyns

Neurology 2008;71;1602-1608; originally published online Aug 20, 2008;

DOI: 10.1212/01.wnl.0000327822.52212.c7

This information is current as of January 30, 2009

The online version of this article, along with updated information and services, is located on the World Wide Web at:

http://www.neurology.org/cgi/content/full/71/20/1602

Neurology ${ }^{\circledR}$ is the official journal of the American Academy of Neurology. Published continuously since 1951, it is now a weekly with 48 issues per year. Copyright $(2008$ by AAN Enterprises, Inc. All rights reserved. Print ISSN: 0028-3878. Online ISSN: 1526-632X.

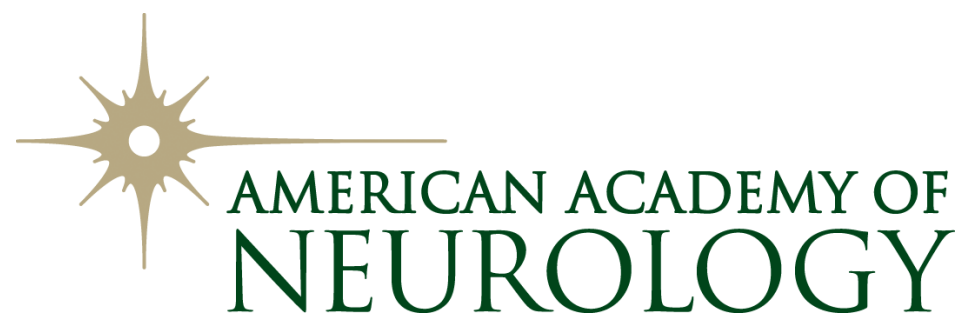




\section{Cobblestone-like brain dysgenesis and altered glycosylation in congenital cutis laxa, Debré type}

L. Van Maldergem, MD

M. Yuksel-Apak, MD

H. Kayserili, MD

E. Seemanova, MD

S. Giurgea, MD

L. Basel-Vanagaite, MD

E. Leao-Teles, MD

J. Vigneron, MD

M. Foulon, MD

M. Greally, MD

J. Jaeken, MD

S. Mundlos, MD

W.B. Dobyns, MD

Address correspondence and reprint requests to Dr. L. Van Maldergem, Centre de Génétique Humaine, CHU Sart-Tilman,

Université de Liège, 4000 Liège, Belgium

vmald@skypro.be
Supplemental data at www.neurology.org

\section{ABSTRACT}

Objective: To delineate a new syndrome of brain dysgenesis and cutis laxa based on the description of 11 patients belonging to nine unrelated families recruited through an international collaboration effort.

Methods: Careful clinical assessment of patients from birth to the age of 23 years with follow-up studies ranging from 3 to 20 years. Biochemical studies of serum proteins glycosylation by isoelectric focusing and capillary zone electrophoresis were performed in 10 patients. Brain MRI studies using conventional methods were analyzed in eight patients.

Results: An expanded clinical spectrum of a syndrome comprising facial dysmorphia (enlarged anterior fontanelles, downward slant of palpebral fissures, prominent root of the nose), a connective tissue disorder (inguinal hernia, hip dislocation, high myopia), and neurologic impairment was defined. Early developmental delay was followed by onset of generalized seizures by the end of the first decade and a subsequent neurodegenerative course. A defect of $\mathrm{N}$ - or $\mathrm{N}$ - plus $\mathrm{O}-$ glycosylation of serum transferrins and ApoClll was observed in 10 patients. An unusual cobblestone-like cortical malformation over the frontal and parietal regions was seen in eight patients and cerebellar abnormalities, including two patients with Dandy-Walker malformation, were observed in three patients.

Conclusions: Our results suggest that autosomal recessive cutis laxa, Debré type, initially considered a dermatologic syndrome, is a multisystemic disorder with cobblestone-like brain dysgenesis manifesting as developmental delay and an epileptic neurodegenerative syndrome. It might represent a metabolic cause of Dandy-Walker malformation. It is associated with a deficient $\mathrm{N}$ - and-O glycosylation of proteins and shares many similarities with muscle-eye-brain syndromes. Neurology ${ }^{\circledR} 2008 ; 71: 1602-1608$

\section{GLOSSARY}

ARCL = autosomal recessive congenital cutis laxa; CZE = capillary zone electrophoresis; DWM = Dandy-Walker malformation; FCMD = Fukuyama congenital muscular dystrophy; IEF = isoelectric focusing; MEB = muscle-eye-brain disease; WWS $=$ Walker-Warburg syndrome

Autosomal recessive congenital cutis laxa (ARCL) represents a heterogeneous group of disorders characterized by redundant skin present from birth. Although dominant inheritance has been described (OMIM 123700), autosomal recessive inheritance is more common, with two distinct subtypes described that differ at the ultrastructural level.

The pulmonary emphysema type of ARCL (ARCL type 1, OMIM 219100) is characterized by fragmentation of elastic fibers, which are present as unassembled primary components. The Debré type (ARCL type 2, OMIM 219200) is characterized by developmental

\footnotetext{
e-Pub ahead of print on August 20, 2008, at www.neurology.org.

From Centre de Génétique Humaine (L.V.M.), CHU Sart-Tilman, Université de Liège, Belgium; Department of Medical Genetics (M.Y.-A., H.K.), Faculty of Medicine, University of Istanbul, Turkey; Department of Clinical Genetics (E.S.), Charles University, Prague, Czech Republic; Department of Neurology (S.G.), CHU Tivoli, La Louvière, Belgium; Department of Medical Genetics (L.B.-V.), Schneider Children's Medical Center, Petah Tikva, Israel; Department of Pediatrics (E.L.-T.), San Joao Hospital, Porto, Portugal; Unité de Génétique Médicale (J.V.), Service de Médecine Néonatale, CHU Nancy, France; Department of Pediatrics (M.F.), CHU Charleroi, Belgium; College of Medicine and Medical Sciences (M.G.), Arabian Gulf University, Manama, Bahrain; Centre for Metabolic Diseases (J.J.), Katholieke Universiteit Leuven, Belgium; Institut für Medizinische Genetik (S.M.), Charité, Campus Virchow, Berlin, Germany; and Departments of Human Genetics, Neurology, and Pediatrics (W.B.D.), The University of Chicago, IL.

Disclosure: The authors report no disclosures.
} 
Figure 1 Photographs of seven patients at different ages show the evolution of the skin phenotype, shown here for patient 1 in A, 2 in B-I and B-II, 9 in C, 10 in D, 3 in E-I and E-II, 11 in F-I through F-II, and 4 in G-I through G-III
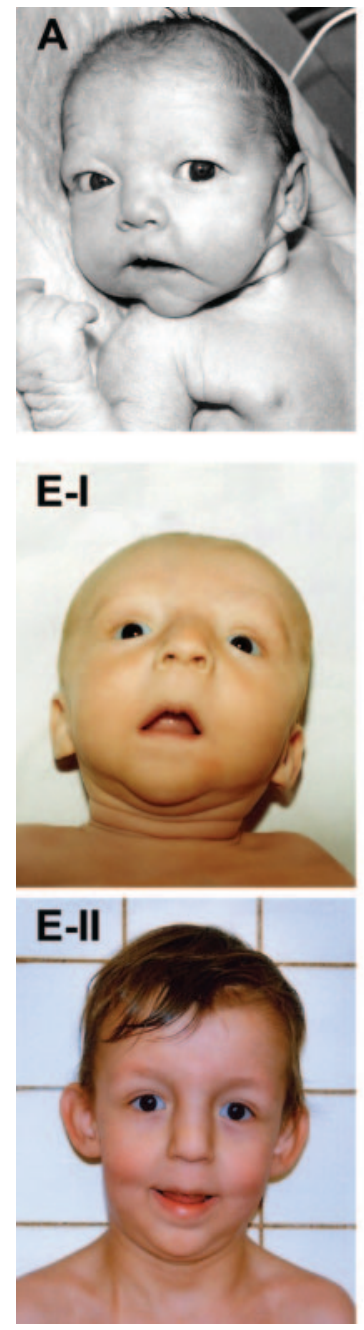
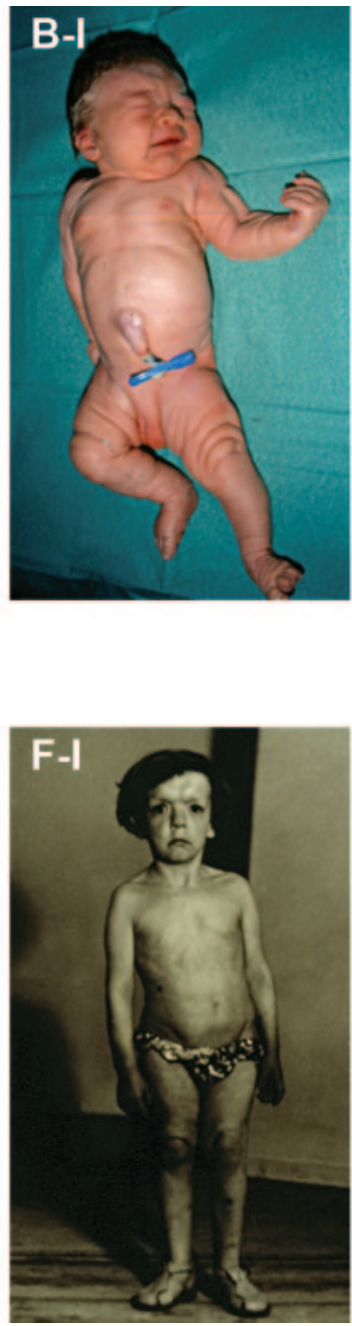
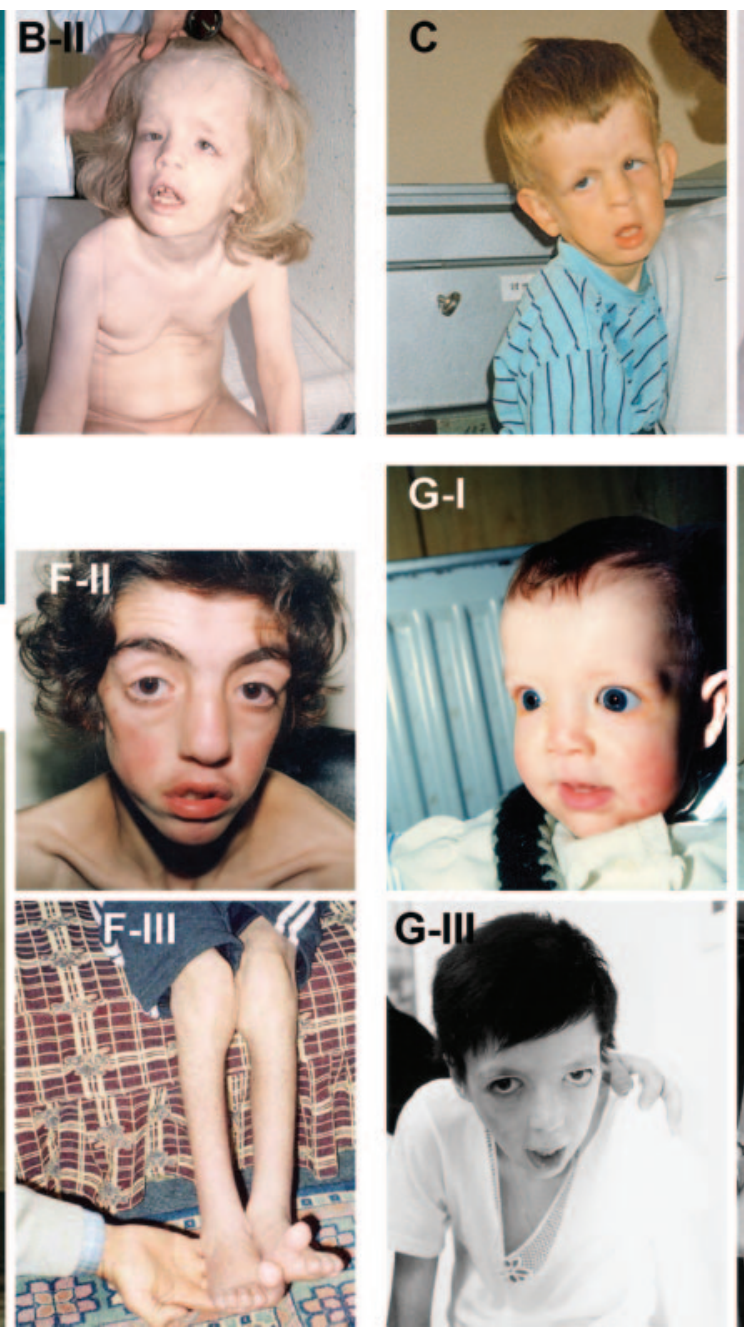
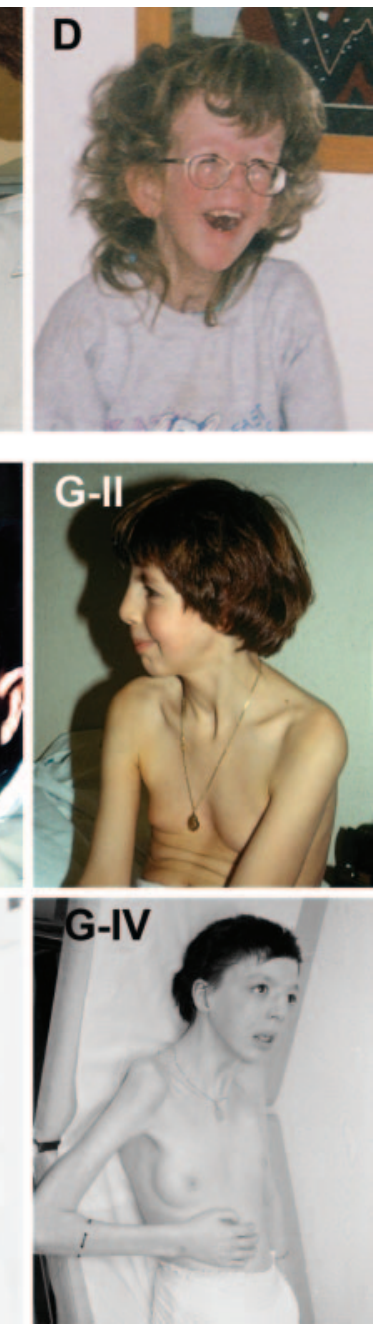

Photographs in infancy $(A, B, E, G)$ show facial dysmorphia with downslanting palpebral fissures and prominent nasal root. Over the next several years, the facial features become more normal, but coarse hair (B-II and D) and hypotonia (F and G-II) are seen. By the second decade, a degenerative course is typically seen with severe hypotonia, drooling, and sometimes muscle wasting (F-III, G-III, and G-IV). Written authorization for publication of the photographs was obtained from the legal guardians of all patients.

delay, large anterior fontanelle, facial dysmorphia, and a paucity of elastic fibers on skin biopsy. ARCL is rare, with fewer than 40 patients with the pulmonary emphysema type and fewer than 50 with the Debré type reported (appendix e-1 on the Neurology ${ }^{\circledR}$ Web site at www.neurology.org). A few other patients have had variant or unspecified phenotypes (appendix e-1). In the pulmonary emphysema subtype, homozygous mutations of EGF-containing fibulin-like extracellular matrix protein 2 (EFEMP2) and both homozygous and heterozygous mutations of Fibulin-5 (FBLN5) have been reported, the latter blurring the distinction between autosomal dominant and recessive forms. ${ }^{1-4}$ Mutations in the elastin (ELN) gene have been reported in six families with autosomal dominant cutis laxa associated with variable aortic aneurisms or pulmonary emphysema. ${ }^{5-9}$ Recently, a Dutch group described N- and O-linked glycosylation defects in three patients with autosomal recessive cutis laxa and developmental delay. ${ }^{10}$

We recently established an international collaboration to further delineate the phenotype and map the causative genes. Here we describe an additional 11 patients from nine families with Debré type ARCL and further delineate the brain and neurologic features.

METHODS Clinical reports. Patient 1. This girl was born to unrelated Belgian parents after a pregnancy complicated by 
Figure 2 In Debré type autosomal recessive congenital cutis laxa, the wrinkles or skin folds are narrow and shallow, especially in comparison to the skin folds in the pulmonary emphysema type
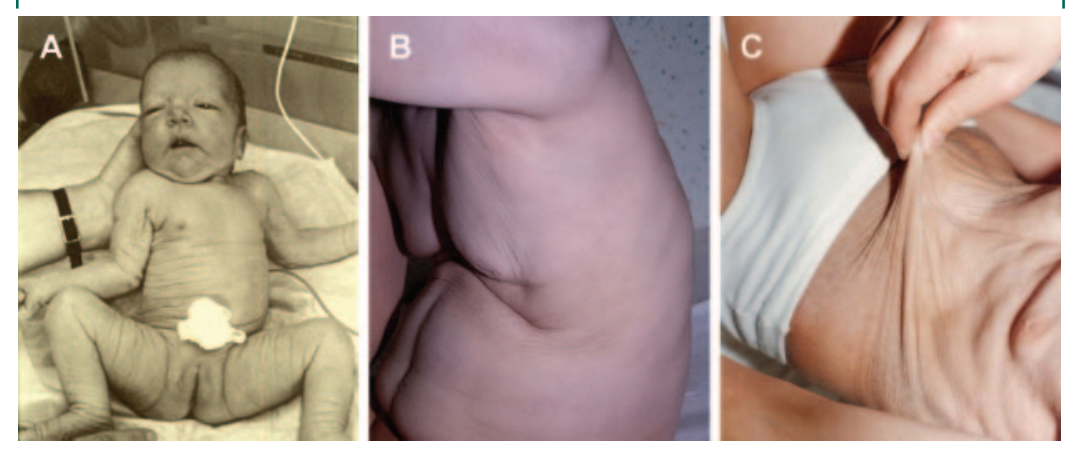

The skin abnormalities are always most prominent in newborns ( $A$, patient 1$)$, then become less marked but still evident at older ages (B, patient 2 at 8 years; $C$, patient 11 at 23 years).

oligohydramnios. Her birthweight was $2,850 \mathrm{~g}$ and birth OFC $31.5 \mathrm{~cm}(-3 \mathrm{SD})$ at 37 weeks gestation. She had a dysmorphic appearance with downslanting palpebral fissures, prominent orbital ridges, and enlarged anterior fontanelle $(7 \times 9 \mathrm{~cm})$, and also generalized overfolding of her skin (figures $1 \mathrm{~A}$ and $2 \mathrm{~A}$ ) consistent with Debré type ARCL. Skin biopsy demonstrated rarefaction of the elastin network with fragmentation and rarity of elastin fibers.

She learned to sit at 1 year and walk late at 2.5 years. She entered mainstream school after 1 year of special education. At 6 years, eye examination detected a focal rupture of the Bruch membrane in her left eye. At 13 years, her weight, height ( -2 standard deviations $[\mathrm{SD}])$, and OFC $(46.5 \mathrm{~cm},-3.5 \mathrm{SD})$ were all small, but she was doing well with no seizures. She had abundant, coarse hair. The cutis laxa became gradually less apparent on serial examinations. Brain MR imaging (figure 3, A through C) shows mildly reduced sulcation and thick cortex in the posterior frontal and possibly anterior parietal regions, short corpus callosum with absent rostrum and thick genu, subtle herniation of the inferior occipital lobe through the tentorial notch to present between the splenium and superior vermis, and mild cerebellar vermis hypoplasia involving primarily the pyramis and uvula.

Patient 2. This girl was born at term to unrelated Belgian parents with birthweight 3,300 $\mathrm{g}$ and OFC $33 \mathrm{~cm}$ (10th centile). Her neonatal history has been already described, including severe cutis laxa, unilateral choanal stenosis, Dandy-Walker malformation (DWM), and hydrocephalus. ${ }^{11}$ Her developmental milestones were delayed. She had marked fatigability, and onset of seizures at 7 years that subsequently proved difficult to control. Serial examinations showed cutis laxa that improved with age, and thick, abundant hair with an uncombable appearance (figures $1 \mathrm{~B}$ and $2 \mathrm{~B}$ ). Her IQ at 10 years was 45 , but serial cognitive testing demonstrated a decline in function.

Her brain MRI (figure 3, D-F) demonstrated reduced sulcation with an irregular cortical surface and mildly thick 7-10 mm cortex over the posterior frontal, perisylvian, and parietal regions, thin white matter, moderately enlarged lateral ventricles, and thin corpus callosum. Lower images showed a short midbrain with small and bent tectum, elongated medulla, severe cerebellar vermis hypoplasia and upward rotation, moderate cerebellar hemisphere hypoplasia, and cystic dilation of the 4 th ventricle resulting in a very large posterior fossa, typical for DWM.

Patients 3 to 11. The clinical histories for patients 3-11 are available as supplemental material in appendix e-2, with photo- graphs in figures 1 and 2, and brain imaging studies in figure 3 and figures e- 1 and e- 2 .

Procedures. Isoelectric focusing (IEF) and capillary zone electrophoresis (CZE) of serum transferrins and IEF of serum apolipoprotein-CIII were performed according to published methods. ${ }^{12-14}$

RESULTS The details of these 11 patients are summarized in the table. All 11 had cutis laxa consistent with Debré type ARCL based on their clinical examination, particularly enlarged anterior fontanelles and typical facial dysmorphia. Skin biopsies demonstrated a sparse elastic network in 9 of 11 patients. Birthweight and length were normal, in contrast to patients in previous reports. Two patients had congenital choanal atresia or stenosis, and five had congenital hip dislocation. Erb's palsy or clavicle fracture was noted in four patients, and corneal dystrophy and sensorineural hearing loss in one patient each.

All had mild to moderate developmental delay and later mental retardation and hypotonia. All teenagers and adults had severe myopia and often strabismus. All but one developed generalized seizures with onset between 8 and 12 years that were often difficult to treat. Several had lower cognitive function after seizure onset, and several had a progressive course including one girl (patient 11) with decline in cognitive function and worsening spasticity and ataxia despite having no seizures.

We reviewed brain MRI in nine patients (table). The most common abnormality was a cortical malformation in eight patients consisting of broad and poorly defined gyri separated by shallow sulci, and abnormally thick 5-10 mm cortex that appeared smooth in some areas and irregular in others, often with vertical streaks within the cortex (figure 3 and figures e-1 and e-2). However, no areas with well-defined microgyri were seen. The cortical malformation appeared most severe in the posterior frontal and anterior parietal lobes including the perisylvian cortex, and extended to the anterior frontal lobe and often the superior temporal lobe. The white matter was normal in most patients, although several had prominent perivascular spaces. The corpus callosum appeared normal in all but one patient, in whom it was abnormally short. Only three patients had cerebellar involvement, including one with isolated vermis hypoplasia and two with DWM consisting of moderate to severe hypoplasia and upward rotation of the vermis, cystic enlargement of the 4th ventricle, and enlarged posterior fossa (figure 3). One girl (patient 11) had generalized cerebral and cerebellar atrophy with no malformations seen (figure e-1, P-R). Several of the brain imaging studies were suboptimal.

IEF of serum sialotransferrins was performed in all but patient 10 -the sib of patient 9 -and 
Figure 3 Representative brain imaging studies in Debré type cutis laxa from patients 1 (A-C), 2 (D-F), and $3(\mathrm{G}-\mathrm{I})$
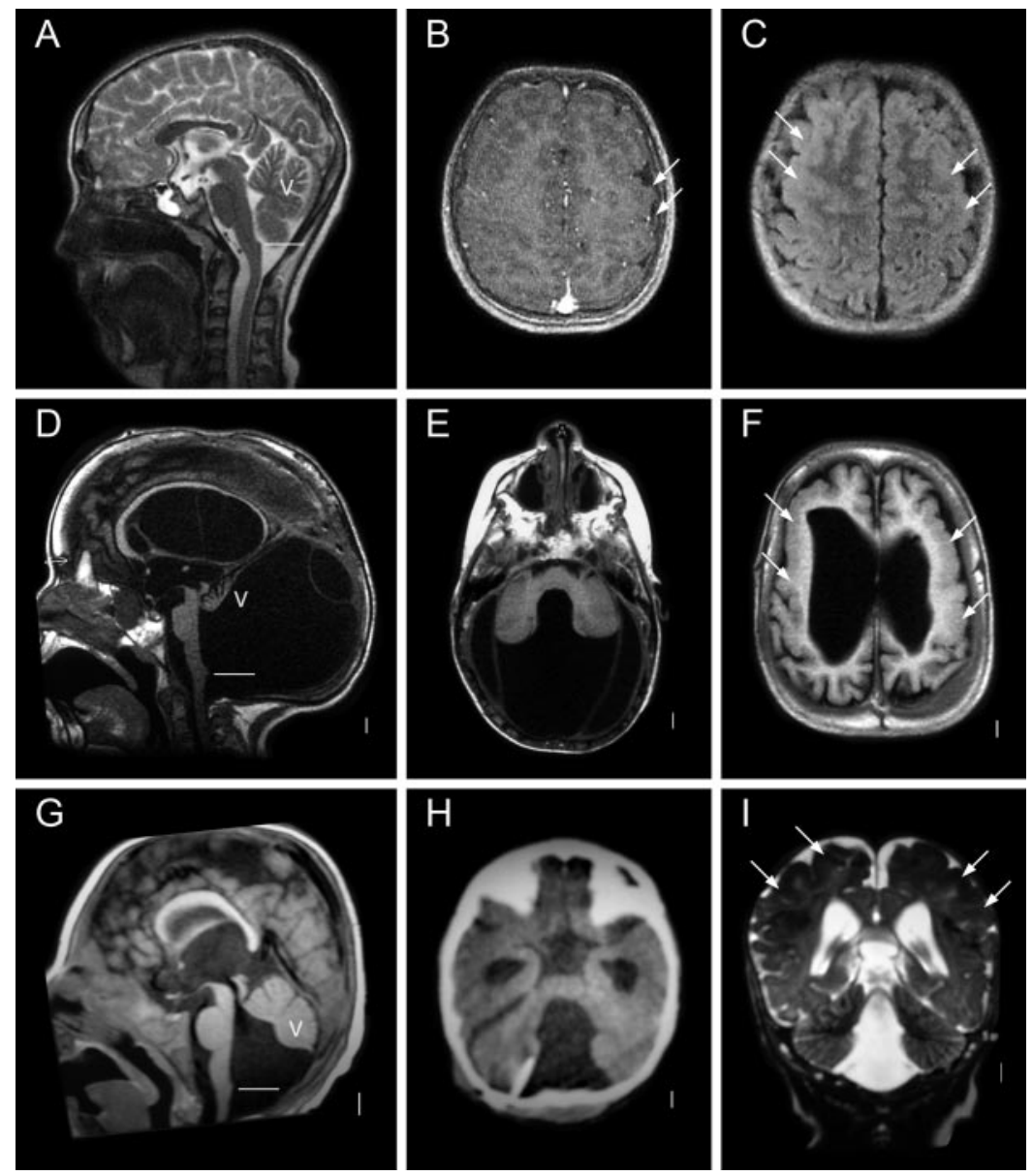

Additional images are shown in figure e-1. In all three of these patients, axial and coronal images at the level of the lateral ventricles demonstrate an abnormally thick 6-10 mm cortex in the frontal and parietal regions on both sides with the frontal pole and posterior parietal regions less severely involved (white arrows in B, C, F). The cortical ribbon appears smooth in some images (I) and irregular in others (see figure e-1), which explains why the cortical malformation has been variably interpreted as pachygyria or polymicrogyria in different patients. Midline sagittal and lower axial images show cerebellar vermis (v) hypoplasia in patients 1-3. This appears as mild hypoplasia of the posterior vermis in patient $1(\mathrm{~A})$, and as typical Dandy-Walker malformation with small and upwardly rotated vermis, cystic dilatation of the 4th ventricle, and enlarged posterior fossa in patients 2 (D, E) and $3(\mathrm{G}, \mathrm{H})$.

showed an abnormal pattern consistent with congenital disorder of glycosylation type 2 (CDG2) with an increase of trisialo- and disialotransferrin (figure 4, B and C). IEF of serum ApoCIII was analyzed in patients 6 and 7 and in their parents. Both affected children showed a clearly lower disialo ApoCIII band than their parents, pointing to hyposialylation (figure 4D). No serum was available from the parents of the other patients, precluding firm conclusions about their ApoCIII patterns.

DISCUSSION Among these 11 patients with Debré type ARCL, we found a recognizable pattern of abnormalities involving facial appearance, connective tissue structures especially the skin, and brain. The most consistent craniofacial abnormalities consisted of an abnormally large anterior fontanelle, prominent supraorbital ridges and nasal root, telecanthus, and downslanting palpebral fissures (figure 1). The skin phenotype was characteristic of cutis laxa with generalized overfolding and wrinkling, but no hyperelasticity as seen in Ehlers-Danlos syndrome. In contrast to the pulmonary emphysema type of ARCL, furrows in the skin are tightly spaced (figure 2). Most patients had abundant coarse hair, and other features indicating a more generalized connective tissue dysplasia such as high myopia or dislocated hips. Skin biopsies supported the diagnosis, showing reduced number and fragmentation of elastin fibers (data not shown). A trend toward improvement of cutis laxa throughout childhood was seen.

All patients had moderately delayed developmental milestones and mental retardation with good social interactions, although special education was required. Generalized seizures began between 6 and 12 years in all patients but one, and were often intractable. The severe seizures probably contributed to shortened survival, with death in childhood occurring in two children reported in the literature and four from our series, all by 17 years. Several patients, especially patient 11 and her two affected sibs, had a progressive course from early childhood characterized by dementia, spasticity, ataxia, and hearing loss that led to death by 9 and 11 years in the two sibs and a bedridden state in patient 11 by 16 years. This distinct clinical course probably correlates with the cerebral atrophy observed on brain imaging.

Brain imaging demonstrated a recurrent pattern of dysgenesis consisting of a cortical malformation in all but one patient, and variable microcephaly and cerebellar hypoplasia (figure 3 and figures e-1 and e-2). The cortical malformation involves the posterior frontal, perisylvian, and parietal regions, and was seen in all but one child. The abnormal cortex partly resembles polymicrogyria, except that the cortical ribbon appears smooth in some areas and irregular in others, with some subtle vertical striations that are never as prominent as in classic polymicrogyria. The cortex is typically $7-10 \mathrm{~mm}$ thick, as in polymicrogyria. Two of the previously reported patients with cutis laxa and CDG type 2 had a similar malformation. ${ }^{10}$ Cerebellar malformations were seen in three of our patients, including $\mathrm{CVH}$ in one girl and DWM in two others. DWM was previously reported in one child with cutis laxa, ${ }^{15}$ but no images of the cerebral cortex or IEF of serum transferrins were presented. Further, DWM and hydrocephalus without the cortical malformation were reported in a boy with severe congenital hypotonia, myopathy, coagulopathy, and CDG type 2 and later associated with 


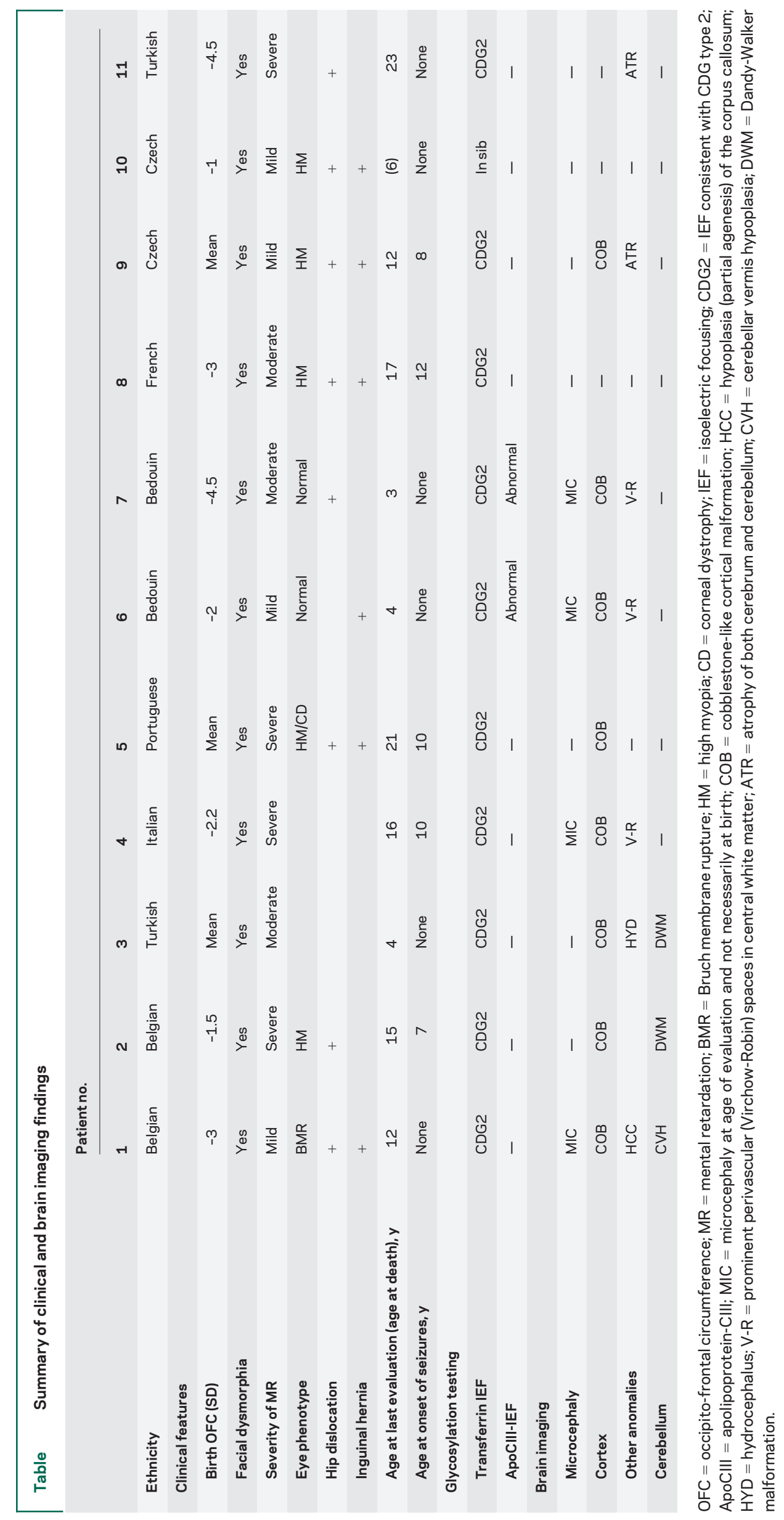


Figure 4 Separation of protein isoforms in autosomal recessive cutis laxa

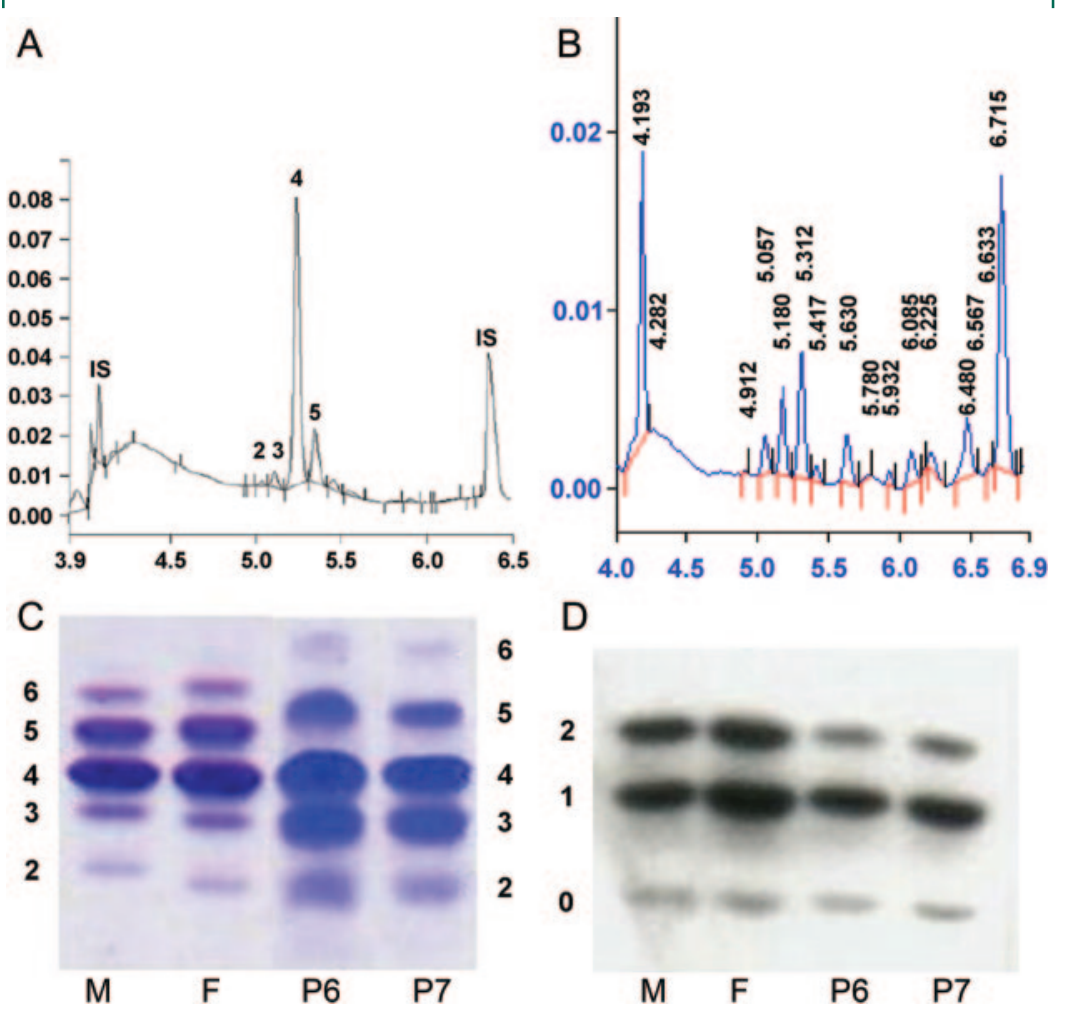

Capillary zone electrophoresis (CZE) in a normal control (A) shows small peaks for disialo(2) and trisialo- (3) transferrins, and a high peak for tetrasialotransferrins (4). CZE in patient 1 (B) demonstrates a pattern typical for type 2 congenital disorders of glycosylation with increased disialo- (peak at 5.057) and trisialo- (peak at 5.180) transferrins, and decreased tetrasialotransferrins (peak at 5.312). Isoelectric focusing (IEF) of serum transferrin pattern in patient $6(P 6)$, patient $7(P 7)$, and their parents $(M$, mother; $F$, father) demonstrate increased size of the peaks for disialo- and trisialotransferrins in the two affected sibs, whereas their parents' profiles are normal (C). The numbers on the left and right indicate the sialotransferrin fractions. IEF of apolipoprotein CIII in the same family (D) shows decreased intensity of disialo fractions with respect to their parents' normal profile.

mutations in the $\beta$-1,4-galactosyltransferase-I or B4GALT1 gene. ${ }^{16,17}$

The cortical malformation seen in eight of our patients resembles the striking cobblestone cortical malformation seen in Walker-Warburg syndrome (WWS), muscle-eye-brain disease (MEB), and Fukuyama congenital muscular dystrophy (FCMD). In these syndromes, the gyral pattern varies from smooth to irregular, and on autopsy the cortex is very disorganized with neurons and glia mixed with fibroblasts and blood vessels in superficial regions. ${ }^{18-20}$ The malformation results from defects in the basal lamina (pial limiting membrane) that allow inappropriate migration of neurons and glia into the subarachnoid space to form extensive marginal glio-neuronal heterotopia. ${ }^{21,22}$ These syndromes are associated with mutations in six genes that encode known or putative O-linked glycosyltransferases: FCMD, FKRP, LARGE, POMGnT1, POMT1, and POMT2.23-28 The encoded proteins are involved in synthesis of alpha-mannosyl side chains of alpha-dystroglycan, which bind to the ex- tracellular matrix protein laminin in retina, brain, and muscle. ${ }^{29-31}$ However, glycosylation of ApoCIII is normal in serum because ApoCIII is synthesized in the liver and apparently not released into the circulation.

The cortical malformation seen in our patients also resembles the malformation seen in two other autosomal recessive syndromes. The first of these is so-called bilateral frontal-parietal polymicrogyria associated with mutations of GPR56. ${ }^{32-34}$ Based on a brain imaging appearance that closely resembles $\mathrm{MEB}$, one of the authors first reported this syndrome as "cobblestone lissencephaly with normal eyes and muscle" in $1996 .{ }^{35}$ Other authors described the same malformation alternatively as pachygyria ${ }^{36}$ or polymicrogyria. ${ }^{33,34,37}$ Interestingly, the GPR56 protein is heavily glycosylated..$^{38}$ The brain imaging appearance also resembles the CEDNIK syndrome caused by mutations in SNAP29. ${ }^{39}$ We suggest using the term frontal predominant or frontoparietal cobblestone-like cortical malformation for these disorders. We hypothesize that the brain malformations observed in Debré type ARCL and these other disorders share a common pathogenesis.

In further support of this analysis, mutations in the a2 subunit of the V-type $\mathrm{H}^{+}$-ATPase (ATPOVOA2) were recently identified in all our patients except for patient $2 . .^{40}$

Received October 3, 2007. Accepted in final form April 4, 2008.

\section{REFERENCES}

1. Loeys B, Van Maldergem L, Mortier G, et al. Homozygosity for a missense mutation in fibulin-5 (FBLN5) results in a severe form of cutis laxa. Hum Mol Genet 2002;11: 2113-2118.

2. Markova D, Zou Y, Ringpfeil F, et al. Genetic heterogeneity of cutis laxa: a heterozygous tandem duplication within the fibulin-5 (FBLN5) gene. Am J Hum Genet 2003;72: 998-1004.

3. Elahi E, Kalhor R, Banihosseini SS, et al. Homozygous missense mutation in fibulin 5 in an Iranian autosomal recessive pedigree and associated haplotype. J Invest Dermatol 2006;126:1506-1509.

4. Hucthagowder V, Sausgruber N, Kim KH, Angle B, Marmorstein LY, Urban Z. Fibulin-4: a novel gene for an autosomal recessive cutis laxa syndrome. Am J Hum Genet 2006;78:1075-1080.

5. Tassabehji M, Metcalfe K, Hurst J, et al. An elastin gene mutation producing abnormal tropoelastin and abnormal elastic fibres in a patient with autosomal dominant cutis laxa. Hum Mol Genet 1998;7:1021-1028.

6. Zhang M-C, He L, Giro M, Yong SL, Tiller GE, Davidson JM. Cutis laxa arising from frameshift mutations in exon 30 of the elastin gene (ELN). J Biol Chem 1999;274: 981-986.

7. Rodriguez-Revenga L, Iranzo P, Badenas P, Puig S, Carrio A, Mila M. A novel elastin gene mutation resulting in an autosomal dominant form of cutis laxa. Arch Dermatol 2004;140:1135-1139. 
8. Urban Z, Gao J, Pope FM, Davis EC. Autosomal dominant cutis laxa with severe lung disease: synthesis and matrix deposition of mutant tropoelastin. J Invest Dermatol 2005;124:1193-1199.

9. Szabo Z, Crepeau MW, Mitchell AL, et al. Aortic aneurismal disease and cutis laxa caused by defects in the elastin gene. J Med Genet 2006;43:255-258.

10. Morava E, Wopereis S, Coucke P, et al. Defective protein glycosylation in patients with cutis laxa syndrome. Eur J Hum Genet 2005;13:414-421.

11. Biver A, De Rijcke S, Toppet V, Ledoux-Corbusier M, Van Maldergem L. Congenital cutis laxa with ligamentous laxity and delayed development, Dandy-Walker malformation and minor heart and osseous defects. Clin Genet 1994;45:318-322.

12. Jaeken J, Van Eijk HG, van der Heul C, Corbeel L, Eeckels R, Eggermont E. Sialic acid-deficient serum and cerebrospinal fluid transferring in a newly recognized genetic syndrome. Clin Chim Acta 1984;144:244-247.

13. Carchon HA, Chevigne R, Falmagne JB, Jaeken J. Diagnosis of congenital disorders of glycosylation by capillary zone electrophoresis. Clin Chem 2004;50:101-111.

14. Wopereis S, Grünewald S, Morava E, et al. Apolipoprotein C-III isofocusing in the diagnosis of genetic defects in O-glycan biosynthesis. Clin Chem 2003;49:1839-1845.

15. Litzman J, Buckova H, Ventruba J, Holcikova A, Mikyska P, Lokaj J. A concurrent occurrence of cutis laxa, DandyWalker syndrome and immunodeficiency in a girl. Acta Paediatr 2003;92:861-864.

16. Hansske B, Thiel C, Lubke T, et al. Deficiency of UDPgalactose: $\mathrm{N}$-acetylglucosamine beta-1,4-galactosyltransferase I causes the congenital disorder of glycosylation type IId. J Clin Invest 2002;109:725-733.

17. Peters V, Penzien JM, Reiter G, et al. Congenital disorder of glycosylation IId (CDG-IId) - a new entity: clinical presentation with Dandy-Walker malformation and myopathy. Neuropediatrics 2002;33:27-32.

18. Williams RS, Swisher CN, Jennings M, Ambler M, Caviness VS Jr. Cerebro-ocular dysgenesis(Walker-Warburg syndrome): neuropathologic and etiologic study. Neurology 1984;34:1531-1541.

19. Dobyns WB, Kirkpatrick JB, Hittner HM, Roberts RM, Kretzer FL. Syndromes with lissencephaly II: WalkerWarburg and cerebro-oculo-muscular syndromes and a new syndrome with type II lissencephaly. Am J Med Genet 1985;22:157-195.

20. Haltia M, Leivo I, Somer H, et al. Muscle-eye-brain disease: a neuropathological study. Ann Neurol 1997; 41:73-80.

21. Miller G, Ladda RL, Towfighi J. Cerebro-ocular dysplasiamuscular dystrophy (Walker-Warburg) syndrome: findings in a 20-week-old fetus. Acta Neuropathol 1991;82: 234-238.

22. Takada K, Nakamura H, Suzumori K, Ishikawa T, Sugiyama N. Cortical dysplasia in a 23 -week fetus with Fukuyama congenital muscular dystrophy (FCMD): a case analysis. Acta Neuropathol 1987;74:300-306.

23. Kobayashi K, Nakahori Y, Miyake M, et al. An ancient retrotransposal insertion causes Fukuyama-type congenital muscular dystrophy. Nature 1998;394:388-389.

24. Beltran-Valero de Bernabe D, Voit T, Longman C, et al. Mutations in the FKRP gene can cause muscle-eye-brain disease and Walker-Warburg syndrome. J Med Genet 2004; $41: \mathrm{e} 61$.
25. Longman C, Brockington M, Torelli S, et al. Mutations in the human LARGE gene cause MDC1D, a novel form of congenital muscular dystrophy with severe mental retardation and abnormal glycosylation of alpha-dystroglycan. Hum Mol Genet 2003;12:2853-2861.

26. Yoshida A, Kobayashi K, Manya H, et al. Muscular dystrophy and neuronal migration disorder caused by mutations in a glycosyltransferase, POMGnT1. Dev Cell 2001;1: 717-724.

27. Beltran-Valero de Bernabe D, Currier S, Steinbrecher A, et al. Mutations in the O-mannosyltransferase gene POMT1 give rise to the severe neuronal migration disorder Walker-Warburg syndrome. Am J Hum Genet 2003;71:1033-1043.

28. van Reeuwijk J, Janssen $M$, van den Elzen C, et al. POMT2 mutations cause alpha-dystroglycan hypoglycosylation and Walker-Warburg syndrome. J Med Genet 2005;42:907-912.

29. Chiba A, Matsumura K, Yamada H, et al. Structures of sialylated O-linked oligosaccharides of bovine peripheral nerve alpha-dystroglycan: the role of a novel O-mannosyl-type oligosaccharide in the binding of alpha-dystroglycan with laminin. J Biol Chem 1997; 272:2156-2162.

30. Henry MD, Satz JS, Brakebusch C, et al. Distinct roles for dystroglycan, beta1 integrin and perlecan in cell surface laminin organization. J Cell Sci 2001;114:1137-1144.

31. Olson EC, Walsh CA. Smooth, rough and upside-down neocortical development. Curr Opin Genet Dev 2002;12: 320-327.

32. Piao X, Hill RS, Bodell A, et al. G protein-coupled receptor-dependent development of human frontal cortex. Science 2004;303:2033-2036.

33. Chang BS, Piao X, Bodell A, et al. Bilateral frontal polymicrogyria: clinical and radiological features in ten families with linkage to chromosome 16. Ann Neurol 2003;56: 596-606.

34. Piao X, Chang BS, Bodell A, et al. Genotype-phenotype analysis of human frontoparietal polymicrogyria syndromes. Ann Neurol 2005;58:680-687.

35. Dobyns WB, Patton MA, Stratton RF, Mastrobattista JM, Blanton SH, Northup H. Cobblestone lissencephaly with normal eye and muscle. Neuropediatrics 1996;27:70-75.

36. Straussberg R, Gross S, Amir J, Gadoth N. A new autosomal recessive syndrome of pachygyria. Clin Genet 1996; 50:498-501.

37. Piao X, Basel-Vanagaite L, Straussberg R, et al. An autosomal recessive form of bilateral frontoparietal polymicrogyria maps to chromosome 16q12.2-q21. Am J Hum Genet 2002;70:1028-1033.

38. Jin Z,Tietjen I, Bu L, et al. Disease-associated mutations affect GPR56 protein trafficking and cell surface expression. Hum Mol Genet 2007;16:1972-1985.

39. Sprecher E, Ishida-Yamamoto A, Mizrahi-Koren M, et al. A mutation in SNAP29, a SNARE protein involved in intracellular trafficking causes a new neurocutaneous syndrome characterized by cerebral dysgenesis, neuropathy, ichthyosis, and palmoplantar keratoderma. Am J Hum Genet 2005;77:242-251.

40. Kornak U, Reynders E, Dimopoulou A, et al., ARCL Debré Study Group. Impaired glycosylation and cutis laxa caused by mutations in the vesicular $\mathrm{H}+$-ATPase subunit ATP6V0A2. Nat Genet 2008;40:32-34. 


\section{Cobblestone-like brain dysgenesis and altered glycosylation in congenital cutis}

laxa, Debré type

L. Van Maldergem, M. Yuksel-Apak, H. Kayserili, E. Seemanova, S. Giurgea, L.

Basel-Vanagaite, E. Leao-Teles, J. Vigneron, M. Foulon, M. Greally, J. Jaeken, S. Mundlos and W. B. Dobyns

Neurology 2008;71;1602-1608; originally published online Aug 20, 2008;

DOI: $10.1212 / 01 . w n 1.0000327822 .52212 . c 7$

This information is current as of January 30, 2009

\begin{tabular}{|ll|}
\hline Updated Information & including high-resolution figures, can be found at: \\
\& Services & http://www.neurology.org/cgi/content/full/71/20/1602 \\
Supplementary Material & Supplementary material can be found at: \\
& http://www.neurology.org/cgi/content/full/01.wnl.0000327822.522 \\
& $12 . c 7 / D C 1$ \\
Subspecialty Collections & This article, along with others on similar topics, appears in the \\
& following collection(s): \\
& MRI \\
& http://www.neurology.org/cgi/collection/mri Metabolic disease \\
& (inherited) \\
& http://www.neurology.org/cgi/collection/metabolic_disease_inherit \\
& ed Developmental disorders \\
& http://www.neurology.org/cgi/collection/developmental_disorders \\
& Cortical dysplasia \\
http://www.neurology.org/cgi/collection/cortical_dysplasia Other \\
neurocutaneous disorders \\
http://www.neurology.org/cgi/collection/other_neurocutaneous_dis \\
orders \\
Information about reproducing this article in parts (figures, tables) \\
or in its entirety can be found online at: \\
http://www.neurology.org/misc/Permissions.shtml \\
Information about ordering reprints can be found online: \\
http://www.neurology.org/misc/reprints.shtml
\end{tabular}

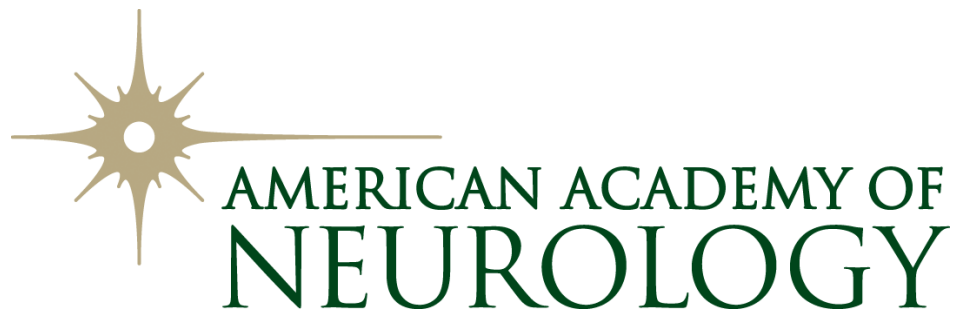

